\title{
First-Year Outcomes after Stroke Rehabilitation: A Multicenter Study in Thailand
}

\author{
Vilai Kuptniratsaikul, ${ }^{1}$ Apichana Kovindha, ${ }^{2}$ Krisna Piravej, ${ }^{3}$ and Piyapat Dajpratham ${ }^{1}$ \\ ${ }^{1}$ Rehabilitation Medicine Department, Faculty of Medicine Siriraj Hospital, Mahidol University, 2 Prannok, Bangkok 10700, Thailand \\ ${ }^{2}$ Rehabilitation Medicine Department, Faculty of Medicine, Chiang Mai University, Chiang Mai 50200, Thailand \\ ${ }^{3}$ Rehabilitation Medicine Department, Faculty of Medicine, Chulalongkorn University, Bangkok 10330, Thailand
}

Correspondence should be addressed to Vilai Kuptniratsaikul; sivkp@mahidol.ac.th

Received 17 May 2013; Accepted 14 June 2013

Academic Editors: K. Hashimoto, J. D. Kingsley, K. Masani, M. Syczewska, and M. Yu

Copyright (C) 2013 Vilai Kuptniratsaikul et al. This is an open access article distributed under the Creative Commons Attribution License, which permits unrestricted use, distribution, and reproduction in any medium, provided the original work is properly cited.

\begin{abstract}
Stroke affects the long-term quality of life and the well-being of patients and families. Stroke patients gain benefits from rehabilitation. Authors reported 1-year outcomes of stroke rehabilitation in 327 patients registered to the Thai Stroke Rehabilitation Registry. The outcomes included death rate, readmission rate, functional ability score (Barthel Index, BI), and factors affecting BI score. Of 327 patients, 214 (65.4\%) had adequate follow-up data for analysis. The average age was $62.1 \pm 12.5$ years, and $57.9 \%$ were male. The mortality rate was $2.5 \%$ and the readmission rate was $11.2 \%$. The number of the patients who could function independently increased from $5.5 \%$ at discharge to $22.9 \%$ and $25.5 \%$ at month 6 and month 12 , respectively. The change in functional ability level of 214 patients included improvement (51.5\%), deterioration (12.8\%), and equivocal (35.7\%). The low functional score at month 12 was significantly correlated with longer length of stay (LOS), longer onset to admission interval, and higher depression score at month-12. In conclusion, approximately half of the patients had an improvement in the disability level for at least one grade at 1-year follow-up. The low functional score by the end of the first year is associated with longer LOS during the first admission, delay in rehabilitation program, and psychological depression.
\end{abstract}

\section{Introduction}

Stroke is one of the leading causes of mortality [1]. It is the most common cause of physical and mental disability in the elderly worldwide, particularly East Asian populations [2]. It affects the long-term quality of life and well-being for both the patients themselves and their families. Stroke patients need medical rehabilitation to enable optimal functions that will overcome the patient's disability. A Canadian guideline in 2008 recommended that all stroke patients should receive rehabilitation therapy as soon as their medical conditions were stable [3]. Rehabilitation for stroke patients has been shown to improve functional ability of stroke survivors and to decrease burden of their families and society [4].

The outcomes of stroke and rehabilitation vary among patients. Teasell et al. revealed, the evidence-based stroke rehabilitation care which is more efficient in functional gain, had fewer complications, had lower mortality rate, and had lower need for institutionalization [5]. The median length of survival among ischemic stroke patients independent in daily living was longer than that of those who are dependent (9.7 years (95\% CI 8.9 to 10.6 ) versus 6.0 years (95\% CI 5.7 to 6.4), resp.) [6]. The result from rehabilitation affects not only longer survival period but also the quality of life of stroke patients for functional independence [6-8].

Thai Stroke Rehabilitation Registry (TSRR) was the first multicentre and hospital-based registry in Thailand. It was founded in 2008 by a group of rehabilitation medicine specialists of six university hospitals and three rehabilitation centres [9]. The patients in TSRR received conventional rehabilitation program including range of motion (ROM) exercise for the paralyzed limb to prevent contracture, strengthening exercise for the sound limb to strengthen muscles, balancing training, and ambulation training if possible. In addition, activities to improve hand functions and self-care training were also rehabilitated. They were discharged from hospitals 
when they reached the rehabilitation goals or when their Barthel Index (BI) scores were stable for 2 consecutive weeks. In 2009, we reported the immediate outcomes of the patients at the time of discharge from rehabilitation wards [10]. In this study, we presented the outcomes of stroke patients in TSRR at the first year after discharge from rehabilitation ward and its correlated factors in order to find the long-term effect of receiving intensive rehabilitation.

\section{Materials and Methods}

The present prospective study was conducted on a cohort of stroke patients in TSRR project which was a multicenter registry established in 2008 [9]. The study was conducted in accordance with the ethical principles stated in the most recent version of the Declaration of Helsinki. The study protocol was approved by the Institutional Review Board of 9 tertiary hospitals.

The outcomes of the rehabilitation inpatient period of 327 patients in TSRR were reported in our previous study [10]. After discharge from rehabilitation ward, the patients were followed up at month 6 and month 12. All patients or their representatives signed an informed consent to release the information for the present study. The inclusion criteria of this study were all subjects from TSRR who could be followed up. The patients whose follow-up data were not available due to any reasons, for example, unable to contact, living in rural areas, or being unable to come to the hospitals, were excluded from the study.

Demographic data including age, sex, type of stroke, bowel/bladder problems, and associated medical diseases of the patients were recorded using a structured record form. The assessment of all outcomes was performed at the hospital setting at month 6 and month 12. At each follow-up visit or appointment, the patients were interviewed or evaluated for the continuing home programs, types of vocations, sources of income, readmission rate, and mortality rate. The patients who were able to come to the hospital were evaluated for self-care and mobility functions using the BI (score 0-20; the higher score means the better functions) [11]. The BI represents severity of disability and is categorized into 5 scales according to the scores. Those were very severely disabled (score 0-4), severely disabled (score 5-9), moderately disabled (score 10-14), mildly disabled (score 15-19), and independent (score 20) [12].

In addition, factors associating with the change of $\mathrm{BI}$ between 1-year follow-up and discharge periods were also explored. Those factors were sex, age, previous stroke, length of stay (LOS), type of stroke, having medical diseases, onset to admission interval, perceptual dysfunctions, having bowel/bladder dysfunctions, having complications during admission from previous study (TSRR), and anxiety and depression scores at month 12 . The anxiety and depression scores were evaluated using the Thai version of the Hospital Anxiety and Depression scale (HADS) [13]. It is composed of 14 items of 2 dimensions of anxiety and depression. The score ranges from 0 to 21 for each dimension. Patients who had a score $\geq 11$ of each part were considered as having clinical anxiety or depression.
TABLE 1: Characteristics of 214 stroke patients.

\begin{tabular}{lc}
\hline Demographic data & Mean \pm SD or $n(\%)$ \\
\hline Age (yrs) & $62.1 \pm 12.5$ \\
Sex: male & $124(57.9)$ \\
Marital status: married & $151(70.6)$ \\
Urban residence & $132(61.7)$ \\
Type of stroke: infarction & $155(72.4)$ \\
Current cigarette smoking & $34(15.9)$ \\
Current alcohol drinking & $63(29.4)$ \\
Presence of dysphagia & $33(15.4)$ \\
Presence of bowel/bladder problems & $65(30.4)$ \\
Associated medical diseases: & \\
(i) Hypertension & $162(75.7)$ \\
(ii) Dyslipidemia & $118(55.1)$ \\
(iii) Diabetes Mellitus & $62(29.0)$ \\
(iv) Cardiac diseases & $40(18.7)$ \\
(v) Previous stroke/TIA & $32(15.0)$ \\
(vi) Others (carotid stenosis, diabetic & \\
retinopathy, hypothyroid, \\
parkinsonism, seizure, \\
spinal stenosis)
\end{tabular}

TIA: transient ischemic attack.

\section{Statistical Analysis}

Data was collected at baseline (discharge period of TSRR project), month 6 , and month 12 and was presented in mean and standard deviation (SD), or number $(n)$ and percent $(\%)$. Kolmogorov-Smirnov test was used to examine the normality of data distribution. The functional ability levels of each visit were compared using Chi-square. Unpaired $t$-test was used to survey the factors associating with the change of BI score. The factors with a $P$ value less than 0.2 were entered into multiple linear regression analysis because there were chances that those might be confounders in a multiple linear regression even though they were not significant in univariate analysis [14].

\section{Results}

Among 327 patients registered in TSRR during October 2008 to September 2009, only 214 patients (65.4\%) could be followed up for at least one-year duration. During the study period, 8 cases $(2.5 \%)$ died, 3 cases $(0.9 \%)$ withdrew, and 102 cases $(31.2 \%)$ were lost to follow up. Causes of death included myocardial infarction (2 cases), chronic renal failure ( 2 cases), hypoglycemic shock (1 case), brain edema (1 case), and unknown causes ( 2 cases). Concerning drop-out analysis, the 214 studied cases and the 102 lost-to-follow-up cases were not different in age, sex, and types of stroke (data not shown).

Demographic data of the 214 patients were presented in Table 1 . The average age was $62.1 \pm 12.5$ years old and $57.9 \%$ were male. Most patients were married (70.6\%) and lived in urban areas $(61.7 \%)$. The majority $(72.4 \%)$ of the patients 
TABLE 2: Continuing treatment programs after discharge and places of treatments of stroke patients at 1-year after discharge $(N=202)$.

\begin{tabular}{|c|c|c|c|c|}
\hline \multirow{2}{*}{ Treatment programs } & \multirow{2}{*}{$N(\%)$} & \multicolumn{3}{|c|}{ Places of treatments } \\
\hline & & Hospital & Home & Others \\
\hline ROM exercise $^{@}$ & $179(88.6)$ & $21(11.7)$ & $164(91.6)$ & $6(3.4)$ \\
\hline Balancing training & $144(71.3)$ & $20(13.9)$ & $130(90.3)$ & $4(2.8)$ \\
\hline Herbal spa & $12(5.9)$ & $2(16.7)$ & $6(50.0)$ & $5(41.7)$ \\
\hline Thai traditional massage & $88(43.6)$ & $7(8.0)$ & $57(64.8)$ & $26(29.5)$ \\
\hline Acupuncture & $23(11.4)$ & $19(82.6)$ & $0(0.0)$ & $4(17.4)$ \\
\hline
\end{tabular}

\#Patients may receive treatments in more than one place.

${ }^{\circledR}$ ROM: range of motion exercise.

TABLE 3: Severity of disability of stroke patients at various periods.

\begin{tabular}{lccc}
\hline Severity of disability & Discharge & Month 6 & Month 12 \\
& $N=327$ & $N=175$ & $N=196$ \\
\hline Very severely disabled (BI = 0-4) & $21(6.4 \%)$ & $8(4.6 \%)$ & $6(3.1 \%)$ \\
Severely disabled (BI = 5-9) & $54(16.5 \%)$ & $16(9.1 \%)$ & $21(10.7 \%)$ \\
Moderately disabled (BI = 10-14) & $97(29.7 \%)$ & $41(23.4 \%)$ & $35(17.9 \%)$ \\
Mildly disabled (BI = 15-19) & $137(41.9 \%)$ & $70(40.0 \%)$ & $84(42.8 \%)$ \\
Independent (BI = 20) & $18(5.5 \%)$ & $40(22.9 \%)$ & $50(25.5 \%)$ \\
\hline
\end{tabular}

Data are the number of patients (percentage) and are compared using Chi-square tests.

BI: Barthel Index.

had ischemic stroke. The most common associated medical diseases were hypertension (75.7\%), followed by dyslipidemia (55.1\%), diabetes mellitus (29.0\%), cardiac diseases (18.7\%), and previous stroke (15.0\%). At the end of one year, $15.9 \%$ were still smoking, $29.4 \%$ were drinking alcohol, $15.4 \%$ had dysphagia, and $30.4 \%$ had bowel/bladder problems.

Readmission occurred in 24 patients (readmission rate $=11.2 \%), 19$ cases of single and 5 of double readmission. As the causes of readmission in some patients were more than 1 , the total number of events was 29 including recurrent stroke (6 events), urinary tract infection (7 events), gastrointestinal bleeding ( 3 events), convulsion ( 3 events), heart failure ( 2 events), lung infection (2 events), bradycardia ( 2 events), severe knee pain from osteoarthritis ( 2 events), warfarin overdose (1 event), and hydrocephalus (1 event).

Concerning the continuing programs after discharge from hospital, almost all of the continuing programs, except acupuncture, were home-based rather than institutionalbased programs. The top three programs that patients still performed at home were ROM exercise $(88.6 \%)$, balance training (71.3\%), and Thai traditional massage (TTM, 43.6\%) (Table 2). Only 28 cases (13.1\%) could continue working on their own jobs. Nearly half of them could work full time. The main sources of income came from their relatives (54.5\%), their own pensions (29.1\%), or their spouses' pensions (10.3\%).

Table 3 presents the number (percentage) of patients classified according to the severity of disability level at discharge, month 6 and month 12. The number of the patients who were moderately to severely and very severely disabled decreased while number of the patients who could function independently increased from $5.5 \%$ at discharge to $22.9 \%$ and $25.5 \%$ at month 6 and month 12 respectively. Table 4 shows the association between the severity of disability levels at discharge and at month 12 . Approximately half (101 from $196,51.5 \%)$ of the patients had improvement of the disability level for at least 1 grade, 25 patients (12.8\%) got deterioration whereas $70(35.7 \%)$ had no change in disability level.

Table 5 demonstrates the factors associated with the change in BI score between 1-year follow up and discharge periods. Only 196 from 214 patients have completed data on BI. After using multiple linear regression analysis, LOS $\geq 1$ month, onset to admission interval $\geq 3$ months, and depression score at month 12 of $\geq 11$ were independent factors associating with poor functional score at 1-year follow up period.

\section{Discussion}

Our result showed that the functional outcome (BI) at month 6 and month 12 increased significantly compared to the score at discharge. It may be because most patients continued rehabilitation program at home after discharge. Vibo et al. reported disability level using the BI score of stroke patients at month 12 and found that $31 \%$ of patients were mildly to moderately disabled (BI score $=10-19$ ), $54 \%$ were very severely disabled (BI score $=0-4$ ), and $15 \%$ were independent $(\mathrm{BI}$ score $=20)[15]$. Compared with our results, only $3.1 \%$ were very severely disabled, $60.7 \%$ were mildly to moderately disabled, and $25.5 \%$ could function independently. However, Vibo's data and ours could not directly be compared because the patients in Vibo's study were in acute stage while ours were in a rehabilitation phase. In contrast, our subjects were more stable and able to receive rehabilitation program in an inpatient ward. Therefore, our patients seemed to have better outcomes than Vibo's study.

There are pieces evidence concerning various predictors for the recovery of functional ability during the first year after stroke. Those significant predictors are age and baseline 
TABLE 4: The association between severity of disability at discharge and month $12(N=196)$.

\begin{tabular}{|c|c|c|c|c|c|c|}
\hline \multirow[b]{2}{*}{$\begin{array}{l}\text { Severity of disability at } \\
\text { discharge }\end{array}$} & \multicolumn{5}{|c|}{ Severity of disability at month 12} & \multirow[b]{2}{*}{$P$-value } \\
\hline & $\begin{array}{l}\text { Very severely disabled } \\
\qquad(\mathrm{BI}=0-4)\end{array}$ & $\begin{array}{l}\text { Severely disabled } \\
\qquad(\mathrm{BI}=5-9)\end{array}$ & $\begin{array}{l}\text { Moderately disabled } \\
\qquad(\mathrm{BI}=10-14)\end{array}$ & $\begin{array}{l}\text { Mildly disabled } \\
\qquad(\mathrm{BI}=15-19)\end{array}$ & $\begin{array}{c}\text { Independent } \\
(\mathrm{BI}=20)\end{array}$ & \\
\hline $\begin{array}{l}\text { Very severely disabled } \\
(\mathrm{BI}=0-4)\end{array}$ & 2 & 4 & 2 & 0 & 0 & \\
\hline $\begin{array}{l}\text { Severely disabled } \\
(\mathrm{BI}=5-9)\end{array}$ & 3 & 7 & 7 & 11 & 1 & $<0.001$ \\
\hline $\begin{array}{l}\text { Moderately disabled } \\
(\mathrm{BI}=10-14)\end{array}$ & 1 & 7 & 17 & 32 & 12 & \\
\hline $\begin{array}{l}\text { Mildly disabled } \\
(\mathrm{BI}=15-19)\end{array}$ & 0 & 3 & 9 & 39 & 32 & \\
\hline $\begin{array}{l}\text { Independent } \\
(\mathrm{BI}=20)\end{array}$ & 0 & 0 & 0 & 2 & 5 & \\
\hline
\end{tabular}

Data are number of the patients and are compared using McNemar Chi-square test.

BI: Barthel Index.

disability [15-18]. The study of Khan et al. reported that older age was one of the independent predictors of poor functional outcome with adjusted OR of 2.1 [19]. In our study, the independent factors associated with the improvement in functional score included LOS, onset to admission interval, and depression score. In contrast to previous studies, we did not find the association between the functional score and age. This might be due to the fact that our subjects were younger than others. Moreover, our subjects had high functional score at the time of discharge and nearly half of them were classified as mildly disabled and independent groups. The relatively young patients would have faster recovery resulting in shorter LOS as shown in our data.

Most of our subjects performed continuing home programs, that is, ROM exercise, and balancing and ambulation training after discharge. Consequently, the percentage of mildly disabled to independent groups was higher $(68.3 \%)$ compared to that of moderately to severely and very severely disabled ones $(31.7 \%)$ at 1-year follow up. The rehabilitation outcomes depend on patients' continuing program as reported by Legg et al. [8]. The authors stated that community stroke rehabilitation could reduce the incidence of functional deterioration and maintain or improve activities of daily living (ADL). Van Peppen et al. found strong evidence that taskoriented exercise training could restore balance and gait, and strengthen the lower paretic limb, when applied intensively and early after stroke onset [20]. In addition, stroke survivors got benefit from participation in physical activity and exercise training [21]. All of these pieces of evidences may support the benefits of rehabilitation program for stroke patients. In contrast, Aziz et al. performed the Cochrane review in 2008 to investigate the effect of the long-term therapy-based rehabilitation interventions in functional ability for stroke patients. They found that there was inconclusive evidence on whether therapy-based rehabilitation intervention one year after stroke can affect the proportion of participants who had deteriorated or were dependent in personal activities of daily living. This may due to quality of trial included [22].

Concerning the complementary and alternative medicine (CAM), the most preferable CAM used on our patients was TTM followed by acupuncture. The TTM is popular among Thai people because it provides sense of comfort from muscle relaxation effect. Moreover, TTM is easy to access as this service is available all over our country. Some believe that massage can improve neurological recovery. Apart from massage, acupuncture is also one of the most popular CAMs among Thai people. Some physicians prefer to use acupuncture in addition to the conventional programs for decreasing pain and muscle spasm [23]. It is carried out for 2-3 cycles of treatment with each of 10-12 sessions. In 2007, a metaanalysis by Shiflett revealed that acupuncture was an effective adjunctive treatment for facilitating stroke recovery [24].

The limitation of this study was the only $65.4 \%$ of stroke patients could be followed up for at least one year. As nearly $40 \%$ of our subjects lived in rural areas, the shortage in patients' transportation facility might be the major obstacle to follow-up the patients at the hospitals. However, the first year mortality rate of $2.5 \%$ in our population was much lower than that in other studies whose mortality rates varied from 14 to $44 \%[15-17,25]$. This could be due to a possibility that younger subjects or those with TIA were recruited. There are plenty of evidence showing that the mortality rate increases with age of the patients $[16,17,26]$. Musicco et al. found that the mortality rate in stroke patients increased 2-fold for the 74-years-old patients compared with the 65-years-old parients and the rate increased to 5-fold in the group of patients older than 75-years-old compared with those younger than 65 years old [27]. Liu et al. reported that advanced age was one of the independent predictors for the first year mortality rate (hazard ratio, $\mathrm{HR}=5.65,95 \% \mathrm{CI}=4.54-8.23$ ) [25]. Our subjects were of a younger age group compared to those in other studies. However, the mortality rate in our study may be underestimated due to the large number of patients $(31.2 \%)$ who were lost to follow up. It is possible that some patients may have died in the year following stroke. Therefore, this should be interpreted with caution that our results only represent data of stroke patients who could be followed up. These patients might have better physical condition and higher economical status, and as a result they would have better outcomes than the lost-to-follow-up subjects. 
TABLE 5: Factors associated with the change in Barthel Index (BI) scores ${ }^{\#}$.

\begin{tabular}{|c|c|c|c|c|c|c|}
\hline \multirow[t]{3}{*}{ Variables } & \multicolumn{3}{|c|}{ Univariate analysis } & \multicolumn{3}{|c|}{ Multiple linear regression } \\
\hline & \multicolumn{3}{|c|}{ Change in BI score $\mathrm{e}^{\#}$} & \multirow[b]{2}{*}{$b$} & \multirow[b]{2}{*}{ SE $(b)$} & \multirow[b]{2}{*}{$P$} \\
\hline & $n$ & Mean \pm SD & $P$ & & & \\
\hline \multicolumn{7}{|l|}{ Sex } \\
\hline Female (1) & 83 & $1.90 \pm 3.81$ & 0.486 & - & & \\
\hline Male (0) & 113 & $2.32 \pm 4.32$ & & & & \\
\hline \multicolumn{7}{|l|}{ Age (yr) } \\
\hline$\geq 60$ (1) & 117 & $2.11 \pm 4.21$ & 0.896 & - & & \\
\hline$<60(0)$ & 79 & $2.19 \pm 3.97$ & & & & \\
\hline \multicolumn{7}{|l|}{ Previous stroke } \\
\hline Yes (1) & 28 & $1.57 \pm 5.10$ & 0.428 & - & & \\
\hline No $(0)$ & 168 & $2.24 \pm 3.92$ & & & & \\
\hline \multicolumn{7}{|l|}{ LOS } \\
\hline$\geq 1$ month (1) & 74 & $1.05 \pm 4.20$ & 0.004 & -1.292 & 0.587 & $0.029^{*}$ \\
\hline$<1$ month $(0)$ & 122 & $2.80 \pm 3.91$ & & & & \\
\hline \multicolumn{7}{|l|}{ Type of stroke } \\
\hline Infarction (1) & 142 & $2.06 \pm 4.18$ & 0.633 & - & & \\
\hline Hemorrhage (0) & 54 & $2.37 \pm 3.93$ & & & & \\
\hline \multicolumn{7}{|l|}{ Medical diseases } \\
\hline Yes (1) & 128 & $1.95 \pm 4.06$ & 0.357 & - & & \\
\hline No $(0)$ & 68 & $2.52 \pm 4.18$ & & & & \\
\hline \multicolumn{7}{|l|}{ OAI } \\
\hline$\geq 3 \mathrm{mo}(1)$ & 40 & $0.23 \pm 3.61$ & 0.001 & -1.737 & 0.717 & $0.016^{*}$ \\
\hline$<3 \mathrm{mo}(0)$ & 156 & $2.64 \pm 4.09$ & & & & \\
\hline \multicolumn{7}{|c|}{ Perceptual dysfunction } \\
\hline Presence (1) & 118 & $2.02 \pm 3.94$ & 0.599 & - & & \\
\hline Absence (0) & 78 & $2.33 \pm 4.37$ & & & & \\
\hline \multicolumn{7}{|c|}{ Bowel / bladder problem } \\
\hline Yes (1) & 63 & $2.35 \pm 4.53$ & 0.629 & - & & \\
\hline No $(0)$ & 133 & $2.05 \pm 3.90$ & & & & \\
\hline \multicolumn{7}{|c|}{ Complication at admission } \\
\hline Yes (1) & 92 & $1.75 \pm 4.41$ & 0.208 & - & & \\
\hline No $(0)$ & 104 & $2.49 \pm 3.80$ & & & & \\
\hline \multicolumn{7}{|c|}{ Anxiety score at month-12 } \\
\hline$\geq 11(1)$ & 19 & $0.74 \pm 4.37$ & 0.067 & -0.036 & 1.083 & 0.974 \\
\hline$<11(0)$ & 165 & $2.48 \pm 3.84$ & & & & \\
\hline \multicolumn{7}{|c|}{ Depression score at month-12 } \\
\hline$\geq 11(1)$ & 37 & $0.87 \pm 4.11$ & 0.009 & -1.684 & 0.813 & $0.040^{*}$ \\
\hline$<11(0)$ & 146 & $2.72 \pm 3.75$ & & & & \\
\hline
\end{tabular}

\# Change in BI: BI score at 1-year FU-BI score at DC.

LOS: length of stay, OAI: onset to admission interval means time between stroke and being transferred from acute care to a rehabilitation unit.

${ }^{*}$ Statistical significance.

\section{Conclusions}

Approximately half of the patients had an improvement in the disability level for at least one grade at 1-year follow-up compared to those of at discharge. The low functional score by the end of the first year is associated with longer LOS during the first admission, delay in rehabilitation program, and psychological depression.

\section{Conflict of Interests}

The authors declare that they have no conflict of interests.

\section{Acknowledgments}

Authors would like to thank the Thai Stroke Rehabilitation Registry Group for their contribution as site coordinators for 
data collection. This study was supported by the National Research Council of Thailand, the Clinical Research Collaboration Network, and the Royal College of Physiatrists of Thailand, on behalf of the Thai Stroke Rehabilitation Registry Group.

\section{References}

[1] F. Levi, L. Chatenoud, P. Bertuccio, F. Lucchini, E. Negri, and C. L. Vecchia, "Mortality from cardiovascular and cerebrovascular diseases in Europe and other areas of the world: an update," European Journal of Cardiovascular Prevention and Rehabilitation, vol. 16, no. 3, pp. 333-350, 2009.

[2] J. S. Jeng and P. K. Yip, "Epidemiology of cerebrovascular disease in the elderly in East Asia," Geriatrics \& Gerontology International, vol. 4, pp. S198-S201, 2004.

[3] P. Lindsay, M. Bayley, A. McDonald, I. D. Graham, G. Warner, and S. Phillips, "Toward a more effective approach to stroke: Canadian best practice recommendations for stroke care," Canadian Medical Association Journal, vol. 178, no. 11, pp. 14181425, 2008.

[4] S. M. Samuelsson, M. Mähönen, D. Hassaf, J. Isaksen, and G. Berg, "Short-term functional outcome of hospitalised first-ever strokes in Finnmark, Norway in 1998-1999. Results from the Finnmark Stroke Register," International Journal of Circumpolar Health, vol. 60, no. 2, pp. 235-244, 2001.

[5] R. W. Teasell, N. C. Foley, K. L. Salter, and J. W. Jutai, "A blueprint for transforming stroke rehabilitation care in Canada: the case for change," Archives of Physical Medicine and Rehabilitation, vol. 89, no. 3, pp. 575-578, 2008.

[6] K. B. Slot, E. Berge, P. Dorman, S. Lewis, M. Dennis, and P. Sandercock, "Impact of functional status at six months on long term survival in patients with ischaemic stroke: prospective cohort studies," British Medical Journal, vol. 336, no. 7640, pp. 376-379, 2008.

[7] P. Chaiyawat, K. Kulkantrakorn, and P. Sritipsukho, "Effectiveness of home rehabilitation for ischemic stroke," Neurology International, vol. 1, no. 1, pp. 36-40, 2009.

[8] L. Legg, P. Langhorne, A. E. Drummond, J. R. Gladman, P. A. Logan, and M. F. Walker, "Rehabilitation therapy services for stroke patients living at home: systematic review of randomised trials," Lancet, vol. 363, no. 9406, pp. 352-356, 2004.

[9] V. Kuptniratsaikul, A. Kovindha, P. Massakulpan et al., "An epidemiologic study of the Thai Stroke Rehabilitation Registry (TSRR): a multi-center study," Journal of the Medical Association of Thailand, vol. 91, no. 2, pp. 225-233, 2008.

[10] V. Kuptniratsaikul, A. Kovindha, P. Dajpratham, and K. Piravej, "Main outcomes of stroke rehabilitation: a multi-centre study in Thailand," Journal of Rehabilitation Medicine, vol. 41, no. 1, pp. 54-58, 2009.

[11] F. I. Mahoney and D. W. Barthel, "Functional evaluation: the Barthel Index," Maryland State Medical Journal, vol. 14, pp. 6165, 1965.

[12] D. T. Wade and R. L. Hewer, "Functional abilities after stroke: measurement, natural history and prognosis," Journal of Neurology Neurosurgery and Psychiatry, vol. 50, no. 2, pp. 177-182, 1987.

[13] T. Nilchaikovit, M. Lotrakul, and U. Phisansuthideth, "Development of Thai version of Hospital anxiety and depression scale in cancer patients," Journal of The Psychiatric Association of Thailand, vol. 41, pp. 18-30, 1996.
[14] D. W. Hosmer and S. Lemeshow, Applied Logistic Regression, John Wiley, New York, Ny, USA, 1989.

[15] R. Vibo, J. Kõrv, and M. Roose, "One-year outcome after firstever stroke according to stroke subtype, severity, risk factors and pre-stroke treatment. A population-based study from Tartu, Estonia," European Journal of Neurology, vol. 14, no. 4, pp. 435439, 2007.

[16] K. N. Vemmos, M. L. Bots, P. K. Tsibouris et al., "Prognosis of stroke in the south of Greece: 1 year mortality, functional outcome and its determinants: the Arcadia Stroke Registry," Journal of Neurology Neurosurgery and Psychiatry, vol. 69, no. 5, pp. 595-600, 2000.

[17] P. Appelros, I. Nydevik, and M. Viitanen, "Poor outcome after first-ever stroke: predictors for death, dependency, and recurrent stroke within the first year," Stroke, vol. 34, no. 1, pp. 122126, 2003.

[18] G. J. Hankey, K. Jamrozik, R. J. Broadhurst, S. Forbes, and C. S. Anderson, "Long-term disability after first-ever stroke and related prognostic factors in the Perth Community Stroke Study, 1989-1990," Stroke, vol. 33, no. 4, pp. 1034-1040, 2002.

[19] M. Khan, B. Ahmed, M. Ahmed et al., "Functional, cognitive and psychological outcomes, and recurrent vascular events in Pakistani stroke survivors: a cross sectional study," BMC Research Notes, vol. 5, article 89, 2012.

[20] R. P. S. Van Peppen, G. Kwakkel, S. Wood-Dauphinee, H. J. M. Hendriks, P. J. Van der Wees, and J. Dekker, "The impact of physical therapy on functional outcomes after stroke: what's the evidence?" Clinical Rehabilitation, vol. 18, no. 8, pp. 833-862, 2004.

[21] P. D. Thompson, D. Buchner, I. L. Piña et al., "Exercise and physical activity in the prevention and treatment of atherosclerotic cardiovascular disease: a statement from the council on clinical cardiology (subcommittee on exercise, rehabilitation, and prevention) and the council on nutrition, physical activity, and metabolism (subcommittee on physical activity)," Circulation, vol. 107, no. 24, pp. 3109-3116, 2003.

[22] N. A. Aziz, J. Leonardi-Bee, M. Phillips, J. R. Gladman, L. Legg, and M. F. Walker, "Therapy-based rehabilitation services for patients living at home more than one year after stroke," Cochrane Database of Systematic Reviews, no. 2, Article ID CD005952, 2008.

[23] J.-G. Zhao, C.-H. Cao, C.-Z. Liu et al., "Effect of acupuncture treatment on spastic states of stroke patients," Journal of the Neurological Sciences, vol. 276, no. 1-2, pp. 143-147, 2009.

[24] S. C. Shiflett, "Does acupuncture work for stroke rehabilitation: what do recent clinical trials really show?" Topics in Stroke Rehabilitation, vol. 14, no. 4, pp. 40-58, 2007.

[25] X. Liu, G. Xu, W. Wu, R. Zhang, Q. Yin, and W. Zhu, "Subtypes and one-year survival of first-ever stroke in Chinese patients: the Nanjing Stroke Registry," Cerebrovascular Diseases, vol. 22, no. 2-3, pp. 130-136, 2006.

[26] M. V. Shah, "Rehabilitation of the older adult with stroke," Clinics in Geriatric Medicine, vol. 22, no. 2, pp. 469-489, 2006.

[27] M. Musicco, L. Emberti, G. Nappi, and C. Caltagirone, "Early and long-term outcome of rehabilitation in stroke patients: the role of patient characteristics, time of initiation, and duration of interventions," Archives of Physical Medicine and Rehabilitation, vol. 84, no. 4, pp. 551-558, 2003. 


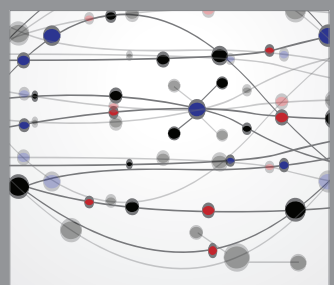

The Scientific World Journal
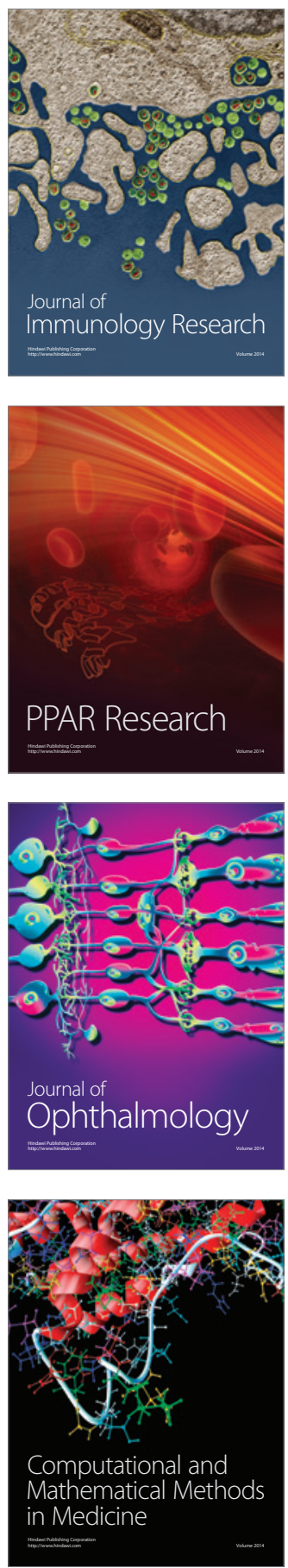

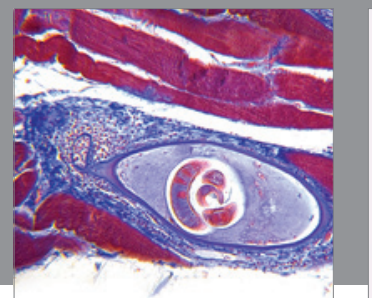

Gastroenterology

Research and Practice
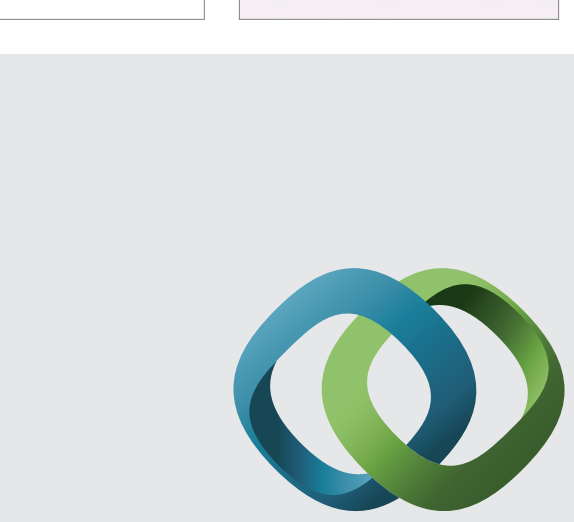

\section{Hindawi}

Submit your manuscripts at

http://www.hindawi.com
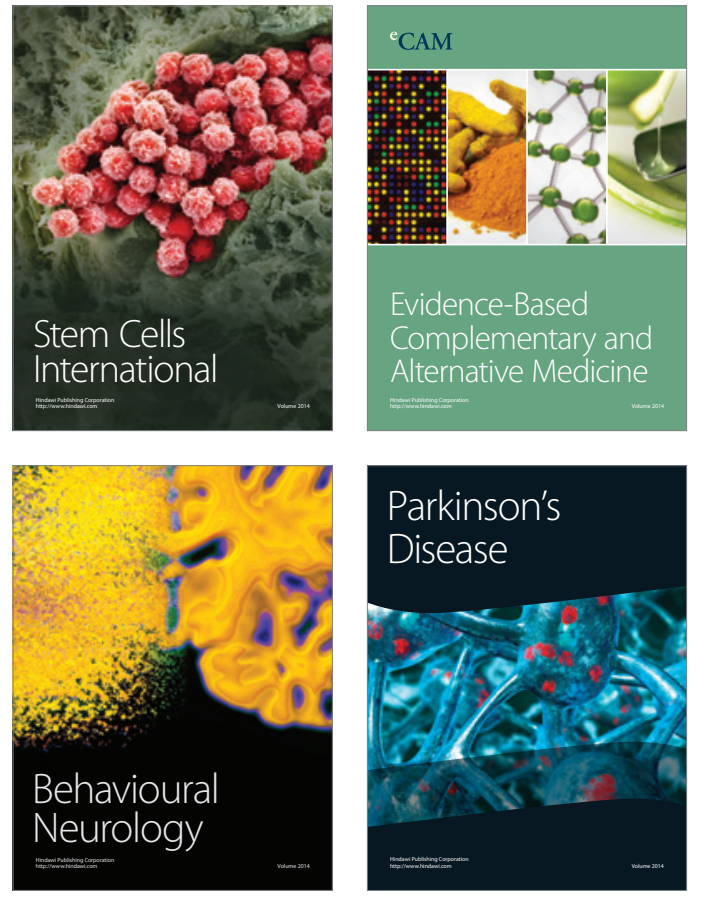
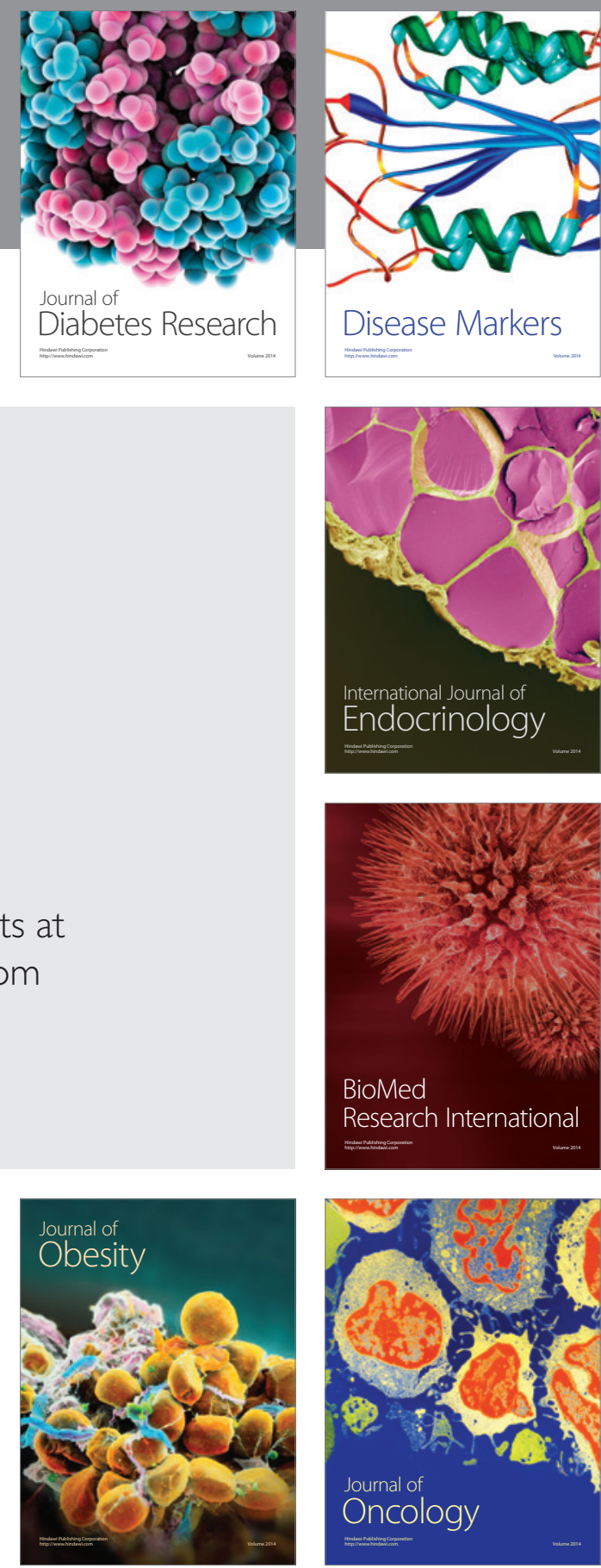

Disease Markers
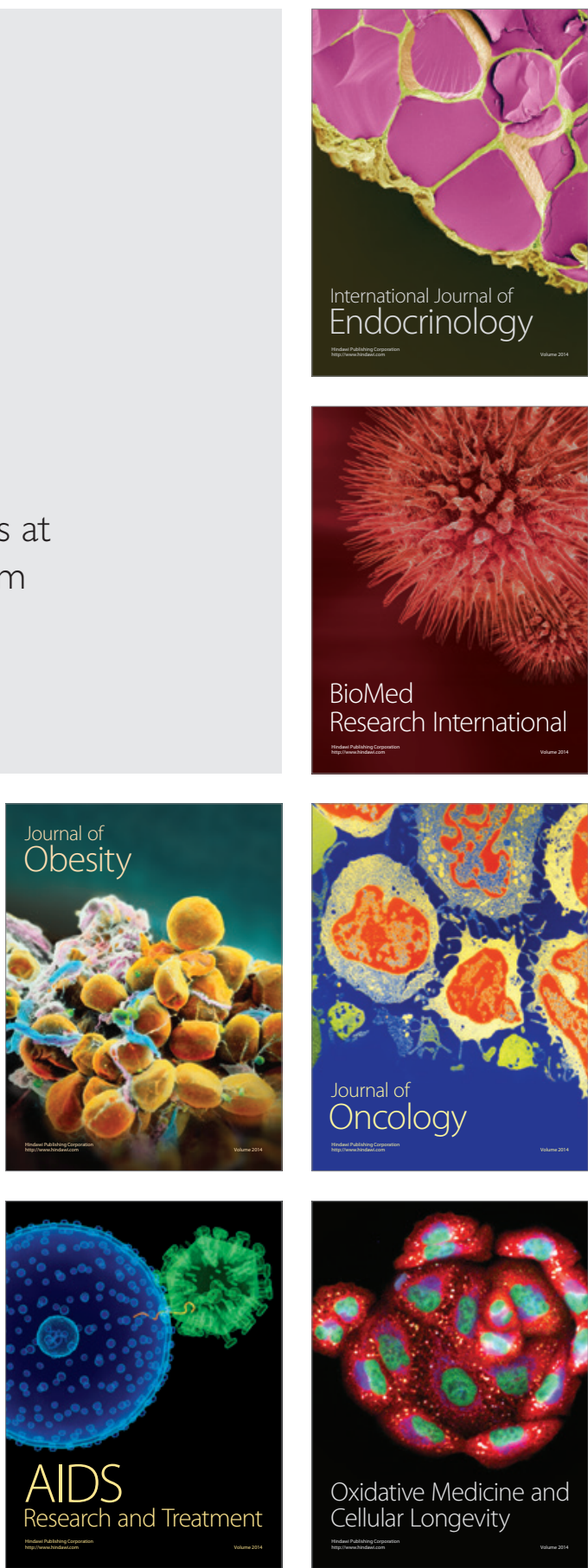